IAN ANGUS

\title{
INTRODUCTION TO A SYMPOSIUM OF WORLD HUMANITIES
}

On January, 27-28, 2012, the Institute for the Humanities at Simon Fraser University (British Columbia, Canada) convened a symposium on the topic "Is There, Can There Be, such an Activity as World Humanities?," which focused on a dialog between European, First Nations and Asian traditions. Since its founding in 1983, the Institute has been largely, though not exclusively, working in contemporary issues within the European intellectual tradition. In recent years, however, it has turned in a new direction, without abandoning its European focus, toward situating contemporary issues within the plurality of cultural traditions from which they can be addressed. The organizing document circulated to invited participants of the Symposium in advance stated, in part:

The current situation of the humanities leads us to ask about the forms of knowledge and the intellectual tradition within which the humanities is embedded: The coming form of planetary unification by political economy raises basic questions about how the many forms of human culture and learning can and will interact-which requires some dialogue between different national and linguistic conceptions of learning in the humanities. The very concept of "humanities" as a form of "culture" in the European tradition depends upon the spirit-nature contrast that is quite different from First Nations and Asian traditions where nature and humanity are seen as more fundamentally interwoven. The idea of "world humanities" is used to pose an issue that requires fundamental thinking, not to suggest that there is any easy synthesis of different traditions of thought and knowledge. Rather, it is to open the hermeneutic project of interpretation to a broad field of traditions now intersecting and sometimes confronting one another.

The Institute invited three senior keynote speakers to set the stage for discussion: Chung-ying Cheng, Professor of Philosophy in the Department of Philosophy at University of Hawaii at Manoa; Leroy Little Bear, member of the Small Robes Band of the Blood Indian Tribe of the Blackfoot Confederacy and professor in the Native American

IAN ANGUS, Professor, Department of Humanities, Simon Fraser University. Specialties: nineteenth and twentieth century European philosophy, Canadian philosophy. E-mail: iangus@sfu.ca 
Studies Department at the University of Lethbridge (1975-1996); and Leslie Armour, Research Professor of Philosophy at the Dominican University College and Professor Emeritus at the University of Ottawa. Each keynote speech was replied to by two speakers grounded in the two other cultural traditions of the humanities. In this way, a dialog between traditions was set up.

The responses to each of the keynote speeches were asked to present not only direct commentary on the addresses but also independent contributions to the theme of the symposium itself. Other strategies of convergence and divergence are explored in these responses. The discussions that ensued were lively and wide ranging, centering on key issues for a contemporary dialog on the idea of world humanities. The relationship between spirit and nature that was mentioned in the announcement was a key component, but also the issues of those too long in exile who have no contemporary possibility of establishing a community based on land, and that of institutional divisions - such as university structure-which lead to difficulties in finding a place for this discussion that our world now demands from the humanities.

The aim of the Symposium was to begin a three-way dialog on fundamental issues in contemporary humanities between three major world traditions: Chinese, Aboriginal, and European. Of course, there are many more important cultural traditions than these three, some of which were represented by the thirty university faculty and independent cultural producers from British Columbia, Canada, (in addition to the nine speakers) who were invited to take part in the discussions. However, it was thought that more than three traditions as a focus would be beyond the capacity of a single two-day meeting. These three were specifically singled out because, in addition to being important on a world scale, they are very live and present in British Columbia. It was hoped that the Symposium would begin a dialog that would continue both locally and globally.

It is by now clear that the interconnected global political economy that is emerging will require basic reflection of the meaning of human life that is carried on in the humanities and that this reflection will need to occur in the context of a plurality of cultural traditions. Since most academics are trained in a single tradition of thought, the Symposium attempted to begin this process of global reflection through a dialog between representatives of different traditions, rather than through directly comparative studies (which are, of course, themselves very important). It was hoped that such a dialog would influence the thinking and teaching of the faculty and cultural workers present over the long term. The Institute for the Humanities will engage in future events intending to serve the same aim. The publication of the papers 
from the Symposium in the Journal of Chinese Philosophy is a welcome opportunity to share this process of intercultural reflection that will be important for the future study and development of Chinese philosophy as well as other cultural traditions from around the globe.

Leroy Little Bear began in the first keynote speech by reminding us of the invisibility of dominated cultures, the necessity they experience of explaining themselves to others, and the difficulty they experience of getting into the conversation as equals. He argued that there is a similarity between the humanities in academia and Aboriginal paradigms of knowledge due to their comparable focus on storytelling and philosophy. His talk went on to focus on the centrality of natural cosmology to the Blackfoot aboriginal paradigm. Rita Wong responded by focusing on water as a primary element for dialog between Aboriginal and Chinese traditions in order to develop a bottom-up approach to the humanities. Ian Angus discussed the role of a European concept of ecology as a basis for dialog with Aboriginal cosmovisions, such as those that have taken on political importance in Latin America, even while noting that this dialog could not imply an identity of perspective.

In the second keynote speech, Leslie Armour undertook an encyclopedic detour through the Western sciences and humanities in order to argue in conclusion that "we need to bring the mind and nature together if we are to bring the humanities to life." Paul Crowe responded by expressing doubts about approaching intercultural convergence through a scientific paradigm and providing adding further examples of convergence between European and Asian philosophy to those mentioned by Armour. However, the categorization of humanistic thought as either "philosophy" or "religion" in European thought is problematic for Chinese philosophy-religion as this distinction does not apply, so that intercultural conversation must extend its questioning to the basic categories with which we structure the conversation. Gordon Christie focused on pinpointing what he calls the assumption of human "exceptionalism" in Armour's analysis, based on a distinction between spirit and nature, that creates a gulf between humans and other animals. In so doing, he clarified a fundamentally difficult point in a potential dialog between European and Aboriginal traditions. He notes in conclusion that if this assumption could be displaced, many of Armour's suggestions for intercultural dialog could be more fruitfully explored.

The third keynote speech by Chung-ying Cheng explored a convergence that he finds between Confucius and Kant in asserting that human autonomy is the source of a morality of benevolence. Mark L. McPherran commented that "Professor Cheng has shown us exactly 
how the activity of global humanities is possible" through comparative studies and responded by providing further examples of convergence between European and Chinese philosophy. He continued by presenting a parallel between Socrates and Confucius in both their historical emergence and their fundamental intention to show that human love must proceed beyond immature self-love to become love of the community. Deanna Reder responded by criticizing the conception of humanism that is used to measure the inadequacy of a civilization oriented exclusively to science and technology and reminds us that it was "the humanist notion of the autonomy of the individual which supplied both an ontological and epistemological basis for the Scientific Revolution and Enlightenment." Consequently, she expresses doubts about a project of world humanities unless it is able to preserve Aboriginal stories and points out that the "unification" of the world is under the sway of international corporations and that our dialog must not suppress the violence of globalization.

In the three keynote contributions, we can see three different models of how an intercultural dialog on world humanities might work. One works through the critique of exclusion, self-explanation, and an offer toward convergence. Another works in a manner necessitated by its tradition-due to the specialization of sciences and arts in the Western tradition and its institutions (such as the university) to work toward a point of potential convergence. A third explores a cross-cultural convergence that is historically precedented. All look toward, and clarify, an important nexus of convergence, but this nexus is approached in different ways that are themselves rooted in differences between the traditions and their actual histories. Although dialog toward convergence is essential, it should not blind us to the violence that is present, sometimes even in the categorical distinctions of the humanities. World humanities, if it is possible, must also be critical in refusing to push for convergence when it comes at the cost of valuable traditions and lessons. It is a difficult task: both precedented in our various traditions as they seek to speak of what is universally human and critical in their awareness that universality is not always genuine but can itself mask particular interests. 